\title{
A Comparative Study of Conservative Management Vs Lord's Anal Dilatation Vs Lateral Sphincterotomy in the Treatment for Chronic Anal Fissure
}

\author{
Hanaa Abdul Kader ${ }^{1}$, Reina Khadilkar², Priti Shah ${ }^{3}$, Maitreyee Save ${ }^{4}$, Inturi Ram Teja ${ }^{5}$ \\ ${ }^{1}$ Post Graduate Resident, Department of General Surgery, ${ }^{2}$ Professor, Department of General Surgery, ${ }^{3}$ Professor, Department \\ of General Surgery, ${ }^{4}$ Post Graduate Resident, Department of General Surgery, ${ }^{5}$ Post Graduate Resident, Department of \\ General Surgery, Dr. D. Y. Patil Hospital and Research Centre, Pimpri, Pune, Maharashtra, India
}

Corresponding author: Dr. Hanaa Abdul Kader, 14 F Cheloor Towers, Poothole P.O., Thrissur 680004, Kerala, India

DOI: http://dx.doi.org/10.21276/ijcmsr.2020.5.2.29

How to cite this article: Hanaa Abdul Kader, Reina Khadilkar, Priti Shah, Maitreyee Save, Inturi Ram Teja. A comparative study of conservative management vs lord's anal dilatation vs lateral sphincterotomy in the treatment for chronic anal fissure. International Journal of Contemporary Medicine Surgery and Radiology. 2020;5(2):B116-B119.

\section{A B S T R A C T}

Introduction: Fissure-in-ano is one of the most common benign anorectal disorders often encountered in surgical outpatient department. The management of this disorder includes non-operative and operative treatments. Study aimed to compare conservative management, lords anal dilatation and lateral sphincterotomy in the management of chronic anal fissure.

Material and Methods: This study was based on analysis of 22 patients with fissure-in-ano who underwent treatment in Dr. D.Y.Patil Medical College, Hospital and Research Centre from November 2018 to February 2019. These patients were divided into three groups based on management received. 8 were managed by conservative management, 7 by anal dilatation and 7 patients were treated by lateral sphincterotomy.

Results: patients who were managed conservatively had immediate pain relief compared to anal dilatation and lateral sphincterotomy. Complications such as head ache and perianal itching were noticed in this group. Recurrence was observed more with conservative management and anal dilatation. Functional results with respect to impaired control of flatus and soiling of underwear were significantly better after sphincterotomy $(P<0002)$.

Conclusion: It is concluded that lateral sphincterotomy is superior to conservative management and anal dilatation as the treatment for idiopathic anal fissure.

Keywords: Anal Dilatation, Anal Fissure, 2\% Diltiazem Ointment, Lateral Sphincterotomy.

\section{INTRODUCTION}

Anal fissure is a very common acute and chronic condition that is presented in majority of the world population. It refers to a longitudinal tear or ulcerated area in the distal anal canal. A chronic fissure is usually deeper and generally has exposed internal sphincter fibers in its base. It is frequently associated with a hypertrophic anal papilla in its proximal aspect and with a sentinel pile at its distal aspect. ${ }^{1}$ It is the most common cause of severe anal pain. The pain may be so severe that patients may avoid defecation for days together, until they are severely constipated. This delay leads to hardening of the stools, which further tears the anoderm during defecation, setting a vicious cycle., ${ }^{2,3}$ Increased tone of the internal anal sphincter, mucosal ischemia along the posterior midline, chronic constipation and injury from hard stools are the factors causing development of chronic fissure in ano.

Treatment of anal fissure focuses on breaking the cycle of pain, spasm, and ischemia. The treatment of anal fissure can be conservative and surgical. ${ }^{4}$ First-line therapy to minimize anal trauma includes bulk agents, stool softeners, and warm seitz baths. ${ }^{5}$ Those who do not achieve a relief from first line conservative management or those who have a recurrence, second line therapy is advocated with botulinum toxin injections or the topical application of ointments such as calcium blockers (nifedipine, diltiazem), or nitric oxide donors (glyceryl trinitrate). Surgical techniques, such as manual anal dilatation or lateral internal sphincterotomy, effectively heal most fissures within a few weeks but may result in permanently impaired anal continence. ${ }^{6}$ The Standard Task Force of the American Society of Colon and Rectal Surgeons has recommended lateral sphincterotomy as the method of choice for the surgical treatment of chronic anal fissures.?

Study aimed to compare conservative management, lords anal dilatation and lateral sphincterotomy in the management of chronic anal fissure.

\section{MATERIAL AND METHODS}

The present prospective study was done on all patients presenting to the hospital with idiopathic acute and chronic anal fissure during November 2018 to February 2019 
were considered for the trial. A total of 22 patients with idiopathic anal fissure were included with the help of simple randomization in this study of conservative management $\mathrm{v} / \mathrm{s}$ simple anal dilatation $\mathrm{v} / \mathrm{s}$ Lateral internal sphincterotomy carried out at our hospital. Altogether 8 by conservative management, 7 by anal dilatation and 7 patients were treated by lateral sphincterotomy. Patients were accepted provided that induration of the edges of the fissure and exposure of the fibres of the internal sphincter in the floor of the fissure were observed on examination.

Conservative management was given by applying $2 \%$ diltiazem ointment topically over the perianal region twice daily for 4-6 weeks.

Dilatation of the anal sphincters was performed as described by Watts et al. ${ }^{8}$ after fitness for anaethesia was given.

Lateral internal sphincterotomy was always performed on the left side with the patient in the lithotomy position after fitness for anaesthesia was given. A small incision was made lateral to the lower edge of the internal sphincter, which was located by the finger. Sharp Mayo's scissors were introduced and passed up between the internal sphincter and the mucosa with the left index finger inserted into the anus. The intersphincteric groove was identified and the inter-sphincteric plane separated with the scissors. The internal sphincter was then cut with the scissors up to the level of the dentate line. The division was confirmed by inserting the pulp of the index finger into the defect. The skin incision was partially closed with a single Chromic Catgut suture.

All patients were allowed home within 24 hours with a dry dressing on the wound and a supply of analgesic tablets. High fibre diet, Stool softeners like syrup cremaffin and seitz bath twice daily for 7 days were adviced to all groups. Patients were seen regularly for weekly interval and attended for final follow up 6 weeks after treatment. No patient was lost to follow up. At follow up symptoms were assessed and the anus examined for signs of recurrence.

\section{Inclusion criteria}

1 All patients of chronic anal fissure who presented to the OPD with pain and spasm.

2 Patients who were fit to undergo SA/GA for the procedure of Lateral Sphincterotomy.

3 Patients who consented to conservative / Surgical management

\section{Exclusion criteria}

1 All paediatric patients

2 Pregnant patients

3 Patients who did not consent to any treatment

4 Patients unfit for SA/GA

Data was entered in excel chart and analysed by chi square test.

\section{RESULTS}

The 22 patients were put into 3 groups. In the group managed by conservative method had an equal gender ratio and a median age of 38 years presenting with symptoms for an average period of 9 months. In the groups managed by lords anal dilatation and lateral sphinterotomy had a median age of 40 and 38 years respectively with an average duration of symptoms for 11 months and 9 months respectively. All the subjects of the three groups were followed up for 6 weeks (Table 1).

Observations were with respect to immediate relief of pain, healing of the anal fissure, surgical complications, and time off work. Satisfactory relief of pain and healing of the fissure was achieved in most of the patients. 7 of the 8 patients that were treated by conservative management came back with recurrence. Complication of topical $2 \%$ diltiazem i.e.

\begin{tabular}{|c|c|c|c|}
\hline & Conservative & Anal dilatation & Lateral sphincterotomy \\
\hline No of patients & 8 & 7 & 7 \\
\hline Male : female & $4: 4$ & $5: 2$ & $4: 3$ \\
\hline Median age & 38 & 40 & 38 \\
\hline Duration of symptoms & 9 months & 11 months & 9 months \\
\hline Follow up time & 6 weeks & 6 weeks & 6 weeks \\
\hline
\end{tabular}

\begin{tabular}{|l|c|c|c|}
\hline & Conservative & Anal dilatation & Lateral sphincterotomy \\
\hline Patients having immediate pain relief & 4 & 6 & 7 \\
\hline Pat ients having complications & 4 & 0 & 0 \\
\hline Median time of healing & 4 weeks & 3 weeks & 3 weeks \\
\hline Number of Recurrence & 7 & 5 & 2 \\
\hline Patients satisfied with spinal anesthesia & - & 7 & 7 \\
\hline Number of days off work & 7 & 2 & 3 \\
\hline \multicolumn{2}{|l|}{ Table-2: Results of treating anal fissure by sphincterotomy, anal dilatation and conservative management } \\
\hline
\end{tabular}

\begin{tabular}{|l|c|c|c|}
\hline & Impaired control of flatus & Impaired control of faeces & Faecal soiling of underwear \\
\hline Lords anal dilatation $(\mathrm{n}=7)$ & 1 & 0 & 2 \\
\hline Lateral sphincterotomy $(\mathrm{n}=7)$ & 0 & 0 & 0 \\
\hline Significance & $\mathrm{P}<0.002$ & $\mathrm{P}<0.002$ \\
\hline \multicolumn{2}{|c|}{} \\
\hline
\end{tabular}


perianal itching and headache were seen in 3 and 1 of the patients respectively managed by conservative treatment. Of the patients in the group treated by anal dilatation, 5 were observed to have a recurrence. All patients with recurrent fissures underwent lateral internal sphincterotomy and the patient discharged from hospital next day (Table 2).

The functional results were better after sphincterotomy than after anal dilatation. 2 out of 7 patients, treated by anal dilatation, faecal soiling was a major problem. Furthermore, 1 of the patient treated by dilatation had impaired control of flatus at the time of follow up, whereas none of the patients treated by lateral internal sphincterotomy suffered from any of these complications ( $p<0.002$ ). Impaired control of faeces was not present in any of the patients in either the groups (Table-3).

\section{DISCUSSION}

In the pathogenesis of anal fissures, which is a painful ulceration of the anal canal mucosa, internal sphincter spasm is an accepted cause as a result of the traumatizing effect of hard and large stools which develops secondary to constipation. It is well-accepted that ischemic events are effective in poor healing and recurrence of anal fissures. ${ }^{9}$ In the patients with anal fissure, anal dilatation, LIS or effective medical treatment decrease the anal canal resting pressure and treat the pain. ${ }^{10-12}$ Our data supports prior studies in the literature with respect to incontinence and recurrence rates, pain relief, satisfaction and healing of patients.

Araujo et al performed a prospective clinical trial with 190 patients in three groups comparing medical treatment $(n: 128)$ vs. LIS ( $n: 62)$ and reported pain relief rates of $100 \%$ for LIS after eighth week (93\% in two weeks and 100\% at the end of the eighth week). ${ }^{13}$ Our study also showed $100 \%$ pain relief following LIS. A study, in which results of Botox and LIS were compared, showed that only $7 \%$ of the patients in LIS group were dissatisfied with their treatment. ${ }^{14}$ This rate was $1 \%$ in a single center study by Salih et al. ${ }^{15}$

However, relapse and the anal incontinence ratio after manual anal dilatation have always been controversial. In literature, healing rate of this method is reported as 83$89 \%$, but recurrence (17\%), sphincter damage (50\%), and anal incontinence (12.5\%) values are represented as serious disadvantages. The shortcomings can be due to uncontrolled approaches in the application of anal dilatation, and it has been stressed that the application should be standardized.

Currently, LIS is a common surgical method which is utilized for the treatment of chronic anal fissure. In the studies of Arroyo et al. after LIS, minor incontinence was found in $5 \%$ of patients, healing occurred in $93-100 \%$ of patients, recurrence occurred in $0-25 \%$ of patients, and incontinence occurred in $0-38 \%$ of patients. ${ }^{16}$

\section{CONCLUSION}

These findings show that lateral internal sphincterotomy is better than conservative management and simple anal dilatation for anal fissure in patients. The recurrence rate of the fissures was significantly less after sphincterotomy, and the functional results with respect to control of flatus and soiling of underwear were significantly better in patients treated by sphincterotomy. Immediate pain relief and recurrence were not in favour of conservative management. The study is open to one criticism that anal dilatation was done under spinal anaesthesia and although it was performed carefully, some believe that spinal anaesthesia does not permit thorough stretching of the sphincters and that deep general anesthesia is required. However in our study except for one patient, all others treated by anal dilatation had immediate relief of pain. It was only in the longer term that the procedure was seen to be inferior to sphincterotomy with respect to the recurrence of fissures. Furthermore, the high incidence of impaired control of flatus and faecal soiling after anal dilatation suggests that the sphincters had been sufficiently stretched with the use of spinal anaesthesia.

Anal fissure is a very common problem worldwide. It causes considerable morbidity and adversely affects the quality of life. Therefore, appropriate treatment is mandatory. Hence we conclude compared with conservative management and anal dilatation, lateral internal sphincterotomy is the treatment of choice for patients with chronic anal fissure.

\section{REFERENCES}

1. Notaras MJ. Lateral subcutaneous sphincterotomy for anal fissure - A new technique. Proc R Soc Med 1969;62(1):713

2. Ahmad N, Aziz M, Faizullah. Closed lateral internal sphincterotomy under local anesthesia in OPD in the treatment of chronic anal fissure. Ann King Edward Med Uni 2004;10(4):11-2.

3. Farooq A, Niaz Z. Comparative study of lateral internal sphincterotomy verses topical glyceryl trinitrate for treatment of fissure-in-ano. Ann King Edward Med Uni 2003;9(4): 278-81.

4. Sokol T, Marks JW Anal fissure (torn rectum) - causes and treatment options.

5. Bullard KM, Rothenberger DA. Colon, rectum and anus. Shwartz's Principles of Surgery; 2005;8(6):281104

6. Bennett RC, Goligher JC. Results of internal sphincterotomy for anal fissure. $\mathrm{Br}$ Med J 1962;2(1):1500-3

7. Lindsay I, Cunningham C, Jones OM, Francis C, Mortensen NJ. Fissurectomy-botulinum toxin: a novel sphincter-sparing procedure for medically resistant chronic anal fissure. Dis Colon Rectum 2004;47(1): 1947-52.

8. Watts JM, Bennett RC, Goligher JC. Stretching of the anal sphincters in the treatment of fissure-in-ano. $\mathrm{Br}$ Med 1965;7(1):342-4.

9. Gupta PJ. Internal anal sphincterolysis for chronic anal fissure: a prospective,clinical, and manometer IC study. Am J Surg 2007;194(1):13-6.

10. Hancke E, Schwaner S. Chronische analfissur operative behandlung mitanaldilatation, excision der analfissur versus laterale sphinkterotomie.Coloproctology 2003;25(2):95-105.

11. Melange M, Colin JF, Van Wymersch T. Anal fissure: Correlation betweensymptoms and manometry before and after surgery.Int J Colorectal Dis 1992;7(2):108-11.

12. Pascual M, Pera M, Courtier R, Gil MJ, Parés D, Puig $\mathrm{S}$, et al. Endosonographicand manometric evaluation of internal anal sphincter in patients with chronicanal 
fissure and its correlation with clinical outcome after topical glyceryltrinitrate therapy.Int J Colorectal Dis 2007;22(8):963-7.

13. S.E. Araujo, M.M. Sousa, P.P. Caravatto, A. HabrGamai, I. Cecconello Early and late results of topical diltiazem and bethanechol for chronic anal fissure: a comparative study Hepato-Gastroenterology 2010;57(1):81-85

14. Mentes, B.B., Irkorucu, O., Akin, M.et al. Comparison of Botulinum Toxin Injection and Lateral Sphincterotomy for the Treatment of Chronic Anal Fissure. Dis Colon Rectum 2003;46(3):232-237.

15. A.M. Salih. Chronic anal fissures: Open Lateral internal sphinterotomy result; a case series study. Annals of medicine and surgery 2017;15(6):56-58.

16. Arroyo A, Perez F, Serrano P, Candela F,Lacueva J, Calpena R. Surgical versus chemical (botulinum toxin) spincterotomy for chronic anal fissure: long-term results of a prospective randomized clinical and manometric study. Am J Surg. 2005; 189(4): 429-434.

Source of Support: Nil; Conflict of Interest: None

Submitted: 22-02-2020; Accepted: 17-05-2020; Published online: 30-06-2020 